\title{
¿Adiós a la teoría de la dependencia? Una perspectiva desde la Argentina ${ }^{1}$
}

Pienso que estamos en los estertores de la teoría y literatura dependentista. Esta teoría ha cumplido un ciclo importante y ha sido el primer ensayo colectivo de formular un cuerpo de hipótesis desde el área latinoamericana. Supongo también que este conjunto de formulaciones hipotéticas, modelos e investigaciones empíricas, no caerán como un todo. Al contrario, articuladas con explicaciones parciales anteriores, nos habrán enriquecido mucho (creo en la acumulación conceptual gradualista de las ciencias sociales). Mis dudas sobre la vigencia inmediata de estas concepciones no se centran tanto en su validez intrínseca, cuanto en algunos excesos cometidos. $Y$ en los peligros ajenos a este tipo de explicaciones.

\section{a) El peligro de la explicación absoluta}

En Ciencias Sociales, siempre habíamos adherido a lo que otros elaboraron. Así fuimos universalistas sin quererlo, es decir entendiendo como categorías universales a las que imaginaron en el "centro". Hubo excepciones por supuesto, tal como ocurrió con algunos ensayistas del siglo xrx, tan inmersos en sus lecturas como en las realidades locales; con Alejandro Bunge -que fue capaz de repensar la problemática argentina de las primeras décadas de este siglo al margen de los cánones intelectuales de su época- y con los primeros informes de CEPAL.

Frente al universalismo copiado, la reacción de la literatura dependentista tuvo algo de provinciano, al menos en sus declaradas expectativas de brindar una explicación zonal fuera de las peligrosas generalizaciones "urbi et orbi". Y la teoría de la dependencia se fue perfilando como una natural respuesta a la presunta validez

\footnotetext{
1Esta reflexión es el fruto de un seminario interdisciplinario -sobre el tema del epígrafe- que se llevó a cabo entre agosto de 1971 y diciembre de 1972. Allí trabajamos juntos economistas, sociólogos, expertos en relaciones internacionales, diplomáticos de carrera, historiadores sociales, científicos, políticos, auditores militares e ingenieros. En el seminario se debatieron aspectos téricos pero se introdujeron "datos" $y$ "hechos". De allí surgieron algunos trabajos individuales. La presente versión, madurada durante un año, fue revisada - y enriquecida- por los doctores Eduardo A. Zalduendo, Luciano Tomassini, y el Lic. Carlos Pérez Llana.
} 
universal del marco funcionalista, y a la "naïveté" histórica de la explicación sobre las etapas del crecimiento económico.

Los primeros autores "dependentistas" fueron sin duda conscientes de las limitaciones explicatorias de esta teoría. De ahí que insistieran en hablar de situaciones de dependencia, más que en construir un "corpus" doctrinario, o un modelo analítico. Pero luego, en manos felices, "la dependencia" llegó a asumir caracteres de absoluto, al punto de convertirse en moda analítica, y en explicación de nuestros males (hasta de los impensables). Cabe pues preguntarse sobre el grado de madurez de una ciencia social que anteayer adhirió acríticamente a dicotomías epistemológicas, ayer a los continuos "tradicional/moderno, feudal/democrático, urbano/rural", y hasta estos días a un nuevo par de alternativas (dependencia/liberación).

Lo peor que le hubiera podido ocurrir a la teoría de la dependencia es convertirse - por obra y gracia de sus usuarios- en un "terrible simplificador". Y es de eso que tendríamos que salvarla. Porque por el camino que vamos la malbaratamos, desdibujándole su intrínseca verdad. Un "sagaz pro-imperialista" habría visto con muy buenos ojos la proletarización intelectual de este tipo de explicaciones: la teoría, convertida en moneda desvalorizada, elevada a "ismo" se degrada.

\section{b) El peligro del escapismo}

El mayor peligro es la facilidad con que inconscientemente podemos identificar a este tipo de relaciones con el "chivo emisario". Y que por ahí caigamos en un fácil externalismo.

Ningún análisis de ciencias sociales se enfrenta con el absoluto. Trata tan sólo de develar algo. El riesgo corrido por el tema de la dependencia ha sido el de convertirse en una explicación tranquilizadora de conciencias, desligadora de responsabilidades. Eso es externalismo. Externalismo es esa actitud inconsciente que nos lleva a tratar de identificar a los "algos" responsables de nuestros males, con la secreta esperanza de que nos resulten ajenos. Ajenos a nuestro yo, a nuestra intinidad, a nuestra intransferible responsabilidad. Así cuanto más nos eviten el análisis introspectivo, cuanto más liberador nos resulten de culpas colectivas, tanto mejor. El externalismo es una forma de escapismo. Nosotros los latinoamericanos, con nuestros excesos verbales, solemos usar de las ideas $y$, antes de convertirlas en acto las sepultamos en un mundo de palabras. A mí me parece que por esta vía vamos en camino de lo mismo.

¿No habría sido mejor revertir el orden temático y centrarlo en 
los grados y capacidad de autonomía? ¿No habría sido más relevante -al menos para algunos de nuestros países- partir de la afirmación de una personalidad colectiva más o menos conculcada?

Tengo para mí que la teoría de la dependencia tiene connotaciones derrotistas. Y me parece hasta de mal tono ese machacón lamento por nuestra presunta quiebra. A no ser, como ocurre, que todo esto se vincule con unas determinadas ideología y estrategia.

EL PROBLEMA METODOLÓGICO DE LA "TEORÍA DE LA DEPENDENCIA": MULTICAUSALIDAD EXPLICATORIA, O ALGUNA FORMA DE REDUCCIONISMO

Dentro de esta literatura específica se deberá distinguir:

a) El cuerpo teórico o conjunto de hipótesis.

b) Investigaciones empíricas sobre relaciones concretas.

Las últimas, es decir, las investigaciones, suelen reposar en análisis efectuados a través del empleo de técnicas adecuadas, y en una interpretación multicausal de los fenómenos sociales. Pero hay un notorio desequilibrio entre investigaciones y teoría, cuantitativa y cualitativamente. En todos los órdenes la teoría sobrepasa a la investigación. Tal vez esto resulte una expresión de los estilos literarios y formas del trabajo intelectual, aún imperantes en el mundo de habla española y portuguesa.

El cuerpo teórico ha tenido dos puntos de apoyo distintos. Para algunos autores se trató de explicitar y actualizar lo antes elaborado sobre la relación "centro/periferia". Para otros, de desarrollar -con mayor o menor grado de flexibilidad-aspectos previstos en la filosofía marxista. Como me cuento entre los que creen en la causación circular de los fenómenos sociales, y en la necesaria articulación pluralista de todas las explicaciones, me preocupa la perspectiva proveniente del reduccionismo marxista.

En efecto, la fundamentación filosófica subyacente a esa literatura teórica implica:

a) El reconocimiento de la interacción de los aspectos estructurales con los superestructurales.

b) El empleo de un método histórico-analítico centrado sobre el desarrollo económico producido en el sistema capitalista mundial, sus respectivos centros y sus correspondientes periferias.

c) La indispensable relación dialéctica entre el análisis y las exigencias de la praxis.

d) La combinación de la teoría del imperialismo con la del conflicto de clases. 
Tal vez por esto, integrando las dos fuentes de formulación teólica, resulte:

19) Que la mayoría de los análisis sobre la dependencia se centran en lo económico, en los problemas conexos de la transferencia de tecnología, el crecimiento de las corporaciones, la exportación de capitales, la incidencia producida en los cambios culturales por los efectos de demostración en los consumos, etc., etc. En cambio, se acordó poca importancia a los estudios de ciencia política, a los márgenes de autonomía que suelen tener muchas decisiones públicas, al Estado-árbitro, y al estudio específico de las relaciones internacionales. Así, y a título de ejemplo, nadie se dedicó a estudiar el uso del derecho de veto en el Consejo de Seguridad (o a la amenaza de su uso, que hace dos años impidió que un latinoamericano fuera secretario general de las Naciones Unidas). $Y$ muy pocos han señalado que ecuatorianos, peruanos, chilenos, argentinos, uruguayos y brasileños logramos "de facto" obtener el reconocimiento de las 200 millas de la plataforma submarina.

Este acento mayoritario en lo económico, se debió no sólo a una fundamentación filosófica, sino al prevalente rol de los economistas en el tratamiento del tema. La carencia de un análisis de relaciones internacionales no deja de ser uno de los puntos más endebles del andamiaje. Tal vez porque no se haya percibido la sustantividad de este tipo de relaciones. I que no se alegue que ejemplos como los que anteceden son ajenos a las ciencias sociales. Porque los límites son imprecisos. Máxime cuando la "dependencia" se formula a partir de las relaciones de mercado ( $\mathrm{Si}$ el formalismo sociológico a lo Simmel pertenece a la paleontología de las ciencias sociales, explicaciones como éstas tienen que cargar con "todos" los instrumentos analíticos. $Y$ no reservarse algunos).

$\left.2^{9}\right)$ Toda teoría debe admitir que el "corpus" de su doctrina pase por el inevitable cedazo del análisis empírico. Esto ocurrió poco en nuestro caso. O al menos buena parte de la investigación empírica se realizó desligada, y hasta partiendo de presupuestos contradictorios al sentir teórico mayoritario. Tal vez porque los análisis teóricos se centraron mucho más en lo estructural que en lo coyuntural, lo general que lo particular. $Y$ de ahí, la gran dificultad para aunar lo uno con lo otro. Esta dificultad se acrecienta para una de las dos fuentes teóricas. Porque el reduccionismo marxista sólo se interesa en el análisis de las relaciones existentes en el interior del sistema capitalista. Tal vez por eso no realizó investigación alguna para determinar qué tipo de lazos económicos, de política internacional, etc., unen a Cuba con la primera potencia socialista.

Esto ha redundado en desmedro de la teoría. No sólo por su inevi- 
table imagen unilateral, sino porque ha perdido la oportunidad - pasando a la investigación empírica- de efectuar comparaciones enriquecedoras.

39) La literatura dependentista combina dos elementos: análisis por un lado, voluntarismo por otro. Es lógico, son las exigencias de la praxis. En la mayoría de los estudios, la actitud voluntarista se centra en un evento que "debe ocurrir" según líneas más o menos previstas: una determinada quiebra en lo internacional, un cierto tipo de fractura en lo interno, interdependientes.

No creo en la ciencia social neutra, ni en la eliminación ascéptica de los valores; considero indispensable explicitar los valores en que se está, y reconocer el carácter instrumental de la ciencia social. Es decir, colocarla al servicio de la comunidad concreta -el tiempo y el espacio que nos toca vivir- para orientarla en la dirección de nuestros amores. Es necesario repetir que el científico social debería ser un servidor, el poseedor de un bien, capaz de revertirlo en beneficio de sus semejantes. A diferencia de otros, el voluntarismo marxista suele ser más complicado: reposa en la creencia de algunas leyes históricas. Luego el discurso dependentista de filiación marxista suele tener una gran coherencia lógica y analítica... no necesariamente avalada por los hechos. Porque la historia está hecha de idas y vueltas, marchas y contramarchas, y si es finalista al largo plazo no tiene porque serlo al corto. Allí radica el problema de los voluntarismos de este tipo. Porque cuando se dan de bruces frente a retrocesos imprevistos, no suelen formular la autocrítica de sus propias rigideces. Y creen que algo falló en el voluntarismo (cuando tal vez radique en el determinismo).

Casi toda esta literatura se identifica con uno de los términos de la opción: absolutismo vs. incrementalismo. Voy a explicarme: quienes sostienen que no hay otras vías de salida para las situaciones de dependencia que la doble fractura, se ubican en la posición más pura; satisfacen mejor a sus auditorios intelectuales, y quedan autojustificados ante su eventual no virtualización. En cambio, casi no hay textos de teoría de la dependencia "incrementalistas". Pero sospecho que tras muchos estudios empíricos sobre algunas relaciones concretas, hay expectativas de ir avanzando poco a poco.

Yo también soy un voluntarista, y creo en la necesidad de realizar investigaciones empíricas tendientes a maximizar nuestros márgenes de autonomía. Porque soy un nacionalista latinoamericano.

$4^{\circ}$ ) En cuanto al uso de la teoría del imperialismo, todo depende de los autores. Hay algunos que parecen olvidar que los famosos 5 puntos de Lenin se basaron en observaciones recogidas entre el fin del siglo y el primer decenio del presente. Menos aún paran 
mientes en que la existencia de una superpotencia socialista ha modificado sustancialmente los datos de aquella envejecida realidad. Y además está China. Por supuesto que la teoría leninista sobre el imperialismo no nos puede explicar nada sobre la competencia inter-países socialistas. Menos aún hubiera podido suponer que una segunda potencia - China- al convertirse en la real antítesis del centro capitalista mundial, desplazaría a la Unión Soviética hacia el tercer término de la relación dialéctica.

En cuanto a la vinculación de esta teoría con la de los conflictos de clase, todo depende del grado de autonomía que se les reconozca a las clases sociales. Pero esto es un problema de fe. Abundan los ejemplos de los imperialismos dividiendo las solidaridades de clase. Y casi no sería necesario recurrir al tan remanido de los obreros alemanes, desolidarizándose de sus pares franceses, ingleses, etc., y apoyando el inicio de la guerra del 14. Aquí más cerca, acabamos de tener un nuevo ejemplo: el de los obreros portuarios de Nueva York alineados detrás de la Standard Fruit, frente a los impuestos sancionados por los países latinoamericanos productores de bananas.

La literatura sociológica contemporánea ha realizado buenos estudios sobre la problemática imperialista. Personalmente adhiero a Ios que la centran en una cambiante prevalencia instrumental según períodos históricos ${ }^{2}$. Así por ejemplo, los que sostienen que imperialismos rudimentarios usaron (y usan) la violencia física como medio para imponer sus puntos de vista. Que imperialismos (como los que tuvo en vista Lenin) usaron y usan de sus poderes económicos; pero que presumiblemente el futuro control imperial radique en la difusión universal de una cultura (convertida en cultura mundial) a través del monopolio y concentración de los medios de comunicación de masas.

\section{ELABOREMTOS UNA DEFINICIÓN OPERACIONAL}

Llama la atención el escaso o ningún interés que ha tenido la teoría de la dependencia en recordar que el mundo es interdependiente, y que las relaciones que nos preocupan no pueden situarse dentro de un continuo "autarquía-interdependencia" simplemente, porque hoy, el primero es inviable.

Sólo hubo autarquía en el Paraguay de los López y en el Japón

2Así por ej. Johan Galtung, "A structural Theory of Imperialism", en Journal of Peace Research, Oslo, 1971, No 2 . Y desde otra perspectiva, pero enmarcando los aspectos de las economías dominantes, François Perroux, Indépendence de la nation, Unión Générale d'Editions, Paris, 1969. 
de los Meiji, apoyados en sus respectivos aislamientos. Hoy el aislamiento implicaría no sólo quedarse al margen del comercio de cosas e ideas, no sólo pretender partir de cero, sino resultar a contrapelo de la historia. Desde el momento en que el hombre trascendió la ley de gravedad, ubicó la faz oculta de Mercurio, y dio fecha fija a su futuro descenso en otro planeta, cualquier forma de ensimismamiento resulta doblemente extemporánea.

Las relaciones de dependencia surgen dentro de un contexto de interdependencia. Son una forma de la interdependencia que se expresa con roles y funciones de distinto tipo. En las relaciones de dependencia hay concentraciones de roles que se identifican con dominio, poder y autoridad; y concentraciones de roles sinónimas de subordinación. Las relaciones de dependencia son aquellas verticales, en cuya virtud un actor " $A$ " que se halla en posición relativamente subordinada a otro " $\mathrm{B}$ ", tiene que hacer algo, o dejar de hacer algo, so pena de privaciones. Hay pues relación vertical, subordinación relativa y sanción potencial. Esta subordinación se debe a la asimetría de sus respectivos poderes. Llámense uso, o amenaza del uso de la fuerza física, dominación o presión económica, control de la información, o de los conocimientos.

De lo anterior podría surgir provisoriamente una definición operacional, que ofrezco para que se pueda interpretar todo lo que habrá de seguir; y es ésta:

"Relaciones de dependencia serían aquellas de subordinación, o que expresen poderes asimétricos, que se manifiestan a partir de la inevitable interdependencia, tanto entre Estados independientes, como entre éstos y organismos públicos y privados, o dentro de unidades regionales, nacionales y locales, coincidente o disímilmente en el interior de los sistemas: político, económico, científico, militar y cultural".

Esta definición operacional pretende ser muy comprensiva; incluye los dos sistemas económicos conocidos -es pues aplicable tanto al capitalismo como al socialismo- y a las relaciones intranacionales. Por último -dentro del área latinoamericana- podría medir las distintas relaciones en cuya virtud a algunos países nos corresponden los roles relativamente dominantes, con relación a otros doblemente periféricos.

Además, la definición parte de una hipótesis de asincronía. Supone que las relaciones de dominación, poderío, etc., no tienen porque ser necesariamente coincidentes, en el mismo momento histórico. Y que éstas varían según se las perciba por sistemas. $Y$ que las verticales que se registren en el interior del uno (económico, por ejemplo) no tienen porque identificarse con las que se den en el otro (cultural, para el caso). El que coincidan o no, que tengan 
la misma metría, o no, todo dependerá de los resultados constatados en la investigación empírica. Esta definición operacional es, pues, provisoria, y pretende ser manuable y general. Tal vez con la expectativa de rescatar por allí la vieja universalidad temática. Es un marco, para ser llenado con datos. Y para ser corregido, en cuanto los datos no coincidan. Porque este es el gran problema de la "teoría de la dependencia", está formulada de un modo asertórico.

\section{CUANDO FALTAN MARCOS DE REFERENCIA}

La falta de marcos de referencia (las relaciones inter-países de la Comunidad Atlántica, o entre los socialistas de Europa Oriental, o para con Israel, etc.) es uno de los grandes déficits de la teoría.

Es cierto que la nuestra comenzó y sigue siendo una explicación sólo regional. $Y$ que, como tal, no podemos exigirle mayores alcances que los que voluntariamente se propuso. Pero a partir de esta autolimitación ¿cuáles son los criterios de comparatibilidad? ¿En relación a qué cosa se puede medir la categoría analítica "dependencia"?

Hay que comparar situaciones y procesos. Entre estos últimos, por la importancia que se le asigna, está el de la orientación y flujo de los capitales norteamericanos invertidos $\mathrm{y} / \mathrm{o}$ reinvertidos, a nivel mundial. Para estos últimos años se podría señalar:

1.9) Que la inversión/reinversión directa de capital norteamericano se distribuyó (1969) en relación de $3 / 4$ del total del flujo, en dirección a los países desarrollados, contra $1 / 4$ hacia los subdesarrollados (incluida Latinoamérica).

$\left.2^{\circ}\right)$ Que también en 1969, y con relación a 1950, Europa experimentó una suba total del monto de la inversión directa norteamericana que le permitió pasar del $14,7 \%$ en 1950 , al $30,5 \%$ del actual. Es decir, en la discriminación por áreas, de los capitales de esa bandera invertidos en el exterior. En América Latina el proceso fue el inverso: descendió el $38 \%$ en 1950, al $19 \%$ actual.

$3^{\circ}$ ) En la dirección de ese flujo de capitales, la constante resultó Canadá. En 1950 había absorbido el $30 \%$ del total de la inversión externa norteamericana, y en 1969 se mantenía en el mismo porcentaje. Como es sabido, en 45 años la situación se ha revertido. En 1929, según el valor declarado en libros de las inversiones directas extranjeras de los Estados Unidos en el mundo, discriminados sus montos por áreas: América Latina ocupaba el primer rango; segundo era el Canadá; tercero Europa, y cuarta, la muy genérica 
categoría de "otros" (Africa, Asia, Australia, etc.). Actualmente la relación es dispar: primero es Canadá y/o Europa según evaluaciones; segundo Europa y/o Canadá; terceros, los "otros", y cuarto América Latina.

49) Algunos especialistas han construido un indicador con el monto total de esas inversiones, sobre el producto bruto generado en un país. Ese podría ser un indicador significativo del grado de dependencia de la economía de una nación con respecto a la importación de capitales de los Estados Unidos. De acuerdo con ese indicador, los países más vulnerables serían: en el primer rango, Panamá y Liberia. A los que les sigue Canadá. El tercer lote lo encabezan Venezuela y Honduras al frente de otros estados latinoamericanos. Y a continuación -aunque por delante de algunos países latinoamericanos- vienen otros países europeos (y de Oceanía) altamente desarrollados. ${ }^{3}$

$\left.5^{\circ}\right)$ Tan importante como el indicador son las proyecciones de este tipo de crecimiento en la inversión (utilizando siempre el mismo criterio: las cifras reconocidas por la Secretaría de Comercio de la Unión sobre las pertenencias de sus conciudadanos en el exterior, medidas sobre el producto bruto). En esa proyección de crecimiento hasta 1980, Bélgica aparece a la cabeza de los otros países desarrollados (con la sola excepción de Canadá). A Bélgica le sigue Gran Bretaña.

El caso de Canadá -país sin fronteras económicas con los Estados Unidos- es el más sintomático. En Canadá -donde en 1969 el monto declarado de la inversión de origen estadounidense superaba los 20.000 millones de dólares- más de la mitad de su economía está bajo el control directo de los intereses de su vecino, a través de las sucursales de las corporaciones multinacionales; y más de los $3 / 4$ de sus importaciones/exportaciones se hacen desde y hacia los Estados Unidos. Además, fruto de lo que algún especialista denominó "síndrome histórico", en Canadá no ha surgido ni una clase capitalista "nacional", ni una inteligencia más o menos autónoma. Así, alentados por un excepcional crecimiento económico, fueron primero herederos de la Corona, se identificaron a partir de 1945 con una vaga ideología internacionalista, y aceptaron luego sin discusión política ni intelectual, su condición presente de socios menores. Pues bien, con esos y otros datos estructurales (por ejemplo, el $95 \%$ de sus patentes pertenecientes a intereses de los Estados Unidos, etc.), Canadá ha tenido en los últimos años un manejo de sus relaciones internacionales contradictorio con algunos de los ob-

${ }^{3}$ Christian Goux et Jean-François Landeau, Le péril américain, Calmann-Levy, París, 1971. 
jetivos declarados por el país dominante. Así su rechazo a romper relaciones con el gobierno de Cuba, incluso en 1962, cuando se discutía el problema de los misiles. Así su continuidad dentro de la alianza británica, y la negativa a ingresar en la Organización de los Estados Americanos. Y cuando hace unos años Canadá quedó incluida en el recargo del $10 \%$ a las importaciones decretado en los Estados Unidos, su "naturaleza caída" le obligó a buscar nuevos mercados.

Pero hay algo más: los futurólogos americanos están contestes en que antes de fin de siglo la potencia mayor de la tierra se verá constreñida a importar agua del Canadá, y por más insólito que parezca, "aire limpio" de sus praderas trigueras.

Indudablemente que el tema de la dependencia es muy complejo y -proyectado hacia el futuro- hasta parecería tener ribetes reversibles. Además, en esta búsqueda de marcos de referencia, ¿dónde incluiríamos a Israel?’ ¿Se podrá individualizar en el mundo capitalista algún caso más englobante que éste (que incluye el libramiento de armas durante y por causa de la guerra, de aviones, la financiación y hasta el convertirse en garante durante y después de la contienda internacional)?

Esto, si no justifica nuestros casos, complica el panorama.

Es evidente que en los últimos años, los países del área -tal vez con las grandes excepciones de Brasil y México- nos hemos convertido en menos interesantes que otros, para la atracción de capitales externos. Y América Latina en su conjunto ha dejado de ser un "mar interior" para devenir aguas procelosas. En parte por nuestras inflaciones crónicas, fundamentalmente por los hechos políticos y las expropiaciones económicas realizadas desde el poder; - la inestabilidad gubernamental, o la inseguridad física de empresas y empresarios generada por los guerrilleros, o las expectativas de nacionalización, o las demandas políticas de más en más acuciantes. De este modo, el área económica de la "Pax Americana" se desplaza hacia regiones menos riesgosas (Europa, Australia) o hacia la Unión Soviética que, entre otras ventajas, asegura la imposibilidad de huelgas.

En los últimos años, entre muchos subdesarrollados y otros de desarrollo intermedio, la regla de acogida a los capitales externos resultaría ser la de inseguridad. Eso es lo que parecería si tomáramos como indicador el tipo de seguros suscritos por las empresas norteamericanas, su cobertura y los riesgos entrevistos de carácter político. Nos estamos refiriendo a las pólizas "Political Risk Insurance", que cubren tanto los riesgos de nacionalización, expropiación y confiscación, como a los originados en hechos bélicos y revolucionarios. Estas pólizas cubren también los daños emergentes de 
disposiciones legales que imposibiliten el total o parcial repatrio de beneficios y dividendos.

Si para las pólizas suscritas en 1969, desagregáramos las correspondientes a la Argentina, resultaría:

19) Que por riesgos de "inconvertibilidad" ocupábamos el segundo rango mundial (primero era Chile, gobierno de Frei), seguidos por Corea, la India y Filipinas en rangos decrecientes, El monto total de los riesgos cubiertos en la Argentina alcanzaba al quinto del total latinoamericano, y a algo más del $10 \%$ mundial.

$2^{\circ}$ ) Por los riesgos de expropiación de esas mismas inversiones, ocupábamos en pleno gobierno militar "de derecha", el tercer rango mundial (detrás de Chile y Guinea, en ese orden), y delante de Corea, la India e Irán. El monto cubierto por ese seguro en la Argentina alcanzaba a un poco más del quinto del total latinoamericano, y al $8 \%$ del mundial.

$3^{\circ}$ ) Por los riesgos de guerra -léase revolución- la Argentina era la tercera en el mundo (tras Corea y Guinea), seguidos del Brasil, India, Colombia y Filipinas, en ese orden. El monto cubierto en la Argentina implicaba la cuarta parte del total asegurado en Latinoamérica, y el $10 \%$ del mundial. ${ }^{4}$

LOS DATOS DE LA REALIDAD RESQUEBRAJAN TODAS LAS TEORÍAS

No nos iremos muy lejos, aunque sobrevolaremos el área. Acaban de producirse una serie de hechos en el mundo que introducen fisuras pronunciadas en la teoría. Es decir, no a la teoría para América Latina, sino a sus presupuestos, a su contexto mayor.

\section{a) El acuerdo Nixon-Brézhnev, "condominio" de supergrandes}

El acuerdo de los SAIT, según los documentos que se han publicado, parecería establecer con sus cuotas fijas de crecimiento balístico y armamenticio, un sistema teórico de recíprocos controles. Eso llevó a muchos especialistas europeos a hablar de una especie de "condominio" armado sobre el mundo, que es en el fondo un nuevo Yalta (o el verdadero Yalta). No importa ahora el grado de escepticismo con que muchos -también europeos- entreven la posibilidad de un real cumplimiento, partiendo del hecho de que las reglas de juego fijadas no serán sin duda las del juego practica-

${ }^{ \pm}$Christian Goux et Jean-François Landeau, op. cit. 
das. Pero por ahora es un documento jurídico fundado en un empate ${ }^{5}$. Ese acuerdo no sólo no impidió la guerra localizada del Medio Oriente, sino que fue su campo de prueba. Guerra que culminó -entre otras cosas - con la toma de conciencia colectiva del formidable poderío militar soviético.

¿Qué cabe pensar entonces de algunos hechos que se nos presentan en cadena, como por ejemplo, los 315.000 soldados norteamericanos -verdaderos rehenes nucleares- estacionados en territorio europeo frente a la suma más grande de divisiones de infantería que haya conocido la historia de la humanidad? ¿Y qué decir de los 2.210 millones de dólares prometidos por la República Federal Alemana a los Estados Unidos para el mantenimiento de esas tropas? ¿Y a la misma suma, que deberán cubrir los restantes 8 países europeos, en los dos años inmediatos subsiguientes? 6

La experiencia histórica nos demuestra que, a partir de 1918, la Unión Soviética solicitó -y obtuvo- cuatro "détentes" de los países capitalistas occidentales, Y que emergió de cada uno de estos reposos con mucha mayor capacidad bélica, poderío económico y aprovechamiento de la tecnología externa incorporada en el lapso.

\section{b) Las empresas transideológicas}

La Fiat, en coparticipación con empresas soviéticas, e instalando plantas en la URSS, pertenece ya a la prehistoria de las relaciones económicas. En cambio, las prospecciones realizadas en la Unión Soviética por la Pepsi-Cola, John Deere e IBM, a la. historia más reciente. $Y$ los acuerdos firmados entre las autoridades soviéticas y la Occidental Petroleum Corporation son de los más relevantes del mundo contemporáneo.

La lista de acuerdos inter-sistemas que podríamos incluir sería muy larga, y no haría más que ratificar lo dicho por Prebisch en 1950, cuando recordó que las ideologías económicas suelen seguir con retraso a los "hechos económicos". Y entre éstos: el préstamo efectuado por el Chase Manhattan Bank, a la Unión Soviética (eI primero en 50 años) para la financiación de una fundición; el acuerdo arribado en 1973 por la ITT y el gobierno soviético para el intercambio de información tecnológica en comunicaciones y electrónica; el contrato ruso-japonés de abril de este año, por un monto de un billón de dólares, destinado a la explotación de recur-

5Entre otros Carl-Friedrich von Weizsacker: "A Sceptical contribution", en The World Order Models Projet, On creating a just order: preferred Worlds for the 1990 s, versión preliminar de circulación restringida.

${ }^{6} \mathrm{En}$ Le Monde Diplomatique, No 241, París, abril, 1974. 
sos naturales (carbón, gas y forestal) en Siberia ${ }^{7}$, para no incluir sino los muy relevantes (están en funcionamiento muchas otras empresas "mixtas" estatal-capitalistas en Yugoslavia, Rumania, Polonia y Hungría).

Cabe recordar que en 1965 la URSS ratificó el Tratado de Marcas y Patentes de París, y que en su consecuencia se abrió en Moscú una oficina para proteger y garantizar las patentes de propiedad industrial extranjera. Los primeros frutos de la política de apertura iniciada por De Gaulle, permitieron al Crédit Lyonnais, a la Societé Générale, y a la Banque de Paris et des Pays-Bas, abrir sus oficinas en Moscú.

Éstos acuerdos económicos y tecnológicos son posibles en tanto y cuanto no afecten lo esencial. Para unos lo esencial radica en la propiedad privada de los medios de producción. Para otros, en la propiedad colectiva. Así, respetándose recíprocamente en sus estatutos jurídicos, el resto resulta común: se trata de organizar economías de escala a la altura de sus mercados (y para la Unión Soviética "también" la de sus expectativas como incipiente sociedad de consumo).

Para el tema que nos aboca, ya no nos interesa tanto la marcha de "ida" (es decir, lo que acabamos de recordar), cuanto el "retorno", la inevitable contrapartida de empresas gigantes soviéticas asociándose con las corporaciones capitalistas, para operar... en el mercado capitalista. Eso es lo que se denomina "empresas multinacionales transideológicas".

\section{c) Diez países árabes evidencian la vulnerabilidad de muchas economías altamente desarrolladas}

Se pueden sacar muchas conclusiones de la denominada "crisis energética". Para lo que aquí nos interesa -es decir el conjunto de hechos modificatorios del repertorio de ideas- vamos a señalar tan sólo algunas.

La actitud árabe -sobrevalorado su "ego" por una media victoria militar- fue discriminatoria. Estados Unidos, que importa poco petróleo árabe, pagó costos bajos. Europa (que adquiere el $48 \%$ del total de las exportaciones de Arabia Saudita), en mucha mayor medida. Dentro de Europa, la situación dramática fue la de Holanda, que debió importar todo su petróleo de los Estados Unidos. Pero, como es sabido, fue un país altamente industrializado el que pagó los mayores costos. Tal Japón, que no había llegado a concertar los detalles de un acuerdo con Irán al momento de la acción

`En Time del 6 de mayo de 1974. 
conjunta de los países islámicos, y que adquiere el $16 \%$ del total de las exportaciones petrolíferas de Arabia Saudita, e importa el $100 \%$ de lo que consume en petróleo.

La primera lección que podríamos extraer es que el sólido bloque constituido por los 10 países exportadores introdujo una modificación sustancial en las reglas del juego imperante; lo que les permitió pasar de personajes de segundo rango en la escena mundial, a reguladores de la economía, el crecimiento y la producción de casi todos los países altamente desarrollados. Así se han convertido en un ejemplo para los otros países del Tercer Mundo, productores de materia prima.

Pero el efecto de demostración es inevitablemente limitado. En parte porque los artículos de primera necesidad que los otros exportan no suelen tener la perentoriedad del petróleo (y alguno, como ocurre con las bananas, son irremediablemente perecederos). Además, porque la cuerda que los árabes han estirado, tiene un punto de ruptura: tenderla más allá de lo debido, implicaría urgir las búsquedas científicas de nuevas fuentes energéticas sustitutivas. Al momento de escribir estas líneas, el "efecto de demostración" originado en la actitud de los países árabes, ha tenido en nuestro medio un principio de ejecutoriedad en el acuerdo de los países exportadores de carne.

La segunda lección que podríamos extraer es ésta: que dependencia es sinónimo de vulnerabilidad. Y que una economía es vulnerable cuando está a merced de los insumos. Sobre todo de los insumos críticos. Así me parece más vulnerable la economía brasileña por tener que importar el $80 \%$ del petróleo que consume, que por el monto total de la inversión industrial externa. $Y$ es ultravulnerable la economía japonesa, aunque sea -entre todas las desarrolladas capitalistas- la menos afectada por la "penetrabilidad" del capital norteamericano.

La tercera consecuencia, es que los intereses de los países subdesarrollados están muy lejos de ser coincidentes. Aunque a veces se expresen en acciones concertadas de tipo diplomático. Y la relación países árabes/petróleo/Brasil, no es la única contradictoria. Porque todos los países subdesarrollados, y pequeños, y no productores de petróleo, han visto multiplicados sus problemas desde que se estableció el nuevo precio.

Para la Argentina también este hecho ha tenido sus efectos secundarios. Uno de los grandes adquirentes de sus carnes industrializadas es Holanda. Holanda -abandonada en la emergencia por Europa- ha tenido que reducir casi drásticamente algunos de sus consumos, comenzando por la dieta. Y la Argentina se ha visto pri- 
vada casi de un momento para otro, de un cliente tradicional. Efecto no querido, sin duda, efecto secundario de los nuevos precios fijados al petróleo.

La cuarta lección es la siguiente: si hubiéramos proyectado al mundo árabe los supuestos generales de la teoría de la dependencia, sólo se podrían haber obtenido resultados satisfactorios de haber combinado eficazmente:

a) Una quiebra en las relaciones mundiales de poder.

b) Una previa fractura interna.

Y sabemos que no es así. La decisión colectiva surgió al quedar "todos" los árabes íntimamente gratificados por los resultados de "esta" guerra. Es público y notorio que en el acuerdo de los exportadores están desde las repúblicas socialistas islámicas, pasando por las monarquías tradicionales, hasta culminar con los regímenes más feudales y despóticos.

d) La dirección y el sentido de la "contracultura" en los países altamente desarrollados capitalistas (y socialistas)

Hemos dicho en otra parte que adheríamos a aquellos autores que -en una distribución temporal de las vías y medios de acción del imperialismo- identificaban al del porvenir con el "neo-neocolonialismo". Y que este "neo-neo..." se expresaría por la tendencia uniformadora en la conformación de la "cultura mundial", a partir de las pautas del país central, y mediante la sujeción y control del sistema de comunicaciones del orbe. Es indudable -para cualquier conocedor de países- que los más vulnerables, los más despersonalizados, y los más tendientes a la identificación con el "modelo" de los Estados Unidos, no son precisamente los nuestros. Al contrario, las identificaciones parecieran resultar de la conjunción favorables de tres factores: niveles económico-sociales correspondientes a los de una sociedad de consumo (por lo menos apareada a las expectativas del "centro"); con las carencias de una identidad nacional unívoca (Canadá, Suiza, Bélgica); más la preexistencia de una cultura similar a la del "centro" (cultura WASP en Australia, Canadá, Nueva Zelandia, etc.).

Así, la conjunción favorable en el mundo capitalista resultaría de la combinación de 3 variables independientes. Pero también se podrían conjugar algunos de estos factores, para tres países socialistas "relativamente abiertos", de discutible unidad nacional (Yugoslavia, Checoslovaquia y Rumania), y con expectativas de sociedades de consumo.

Pero no todo es tan fácil en un mundo e historia de sístoles y 
diástoles, de estímulos y respuestas. Muchos especialistas americanos están contestes en evaluar la magnitud de la "contracultura" generacional en los Estados Unidos (y de Alemania también) con lo que fue para el Imperio Romano el surgimiento de los "contravalores" del incipiente cristianismo. Luego, y mientras nada nos permita develar el futuro de esta inevitable confrontación, vamos a dejar en suspenso la hipótesis de una rápida difusión universal de la cultura técnica de origen norteamericano.

Pero, me pregunto, ¿se ha reflexionado suficientemente sobre el origen, referencias filosóficas, orientaciones del consumo, valores invocados y elementos míticos configurativos de la "contracultura" imperante en los Estados Unidos? ¿Acaso no es el camino de retorno? Su dirección (de los países perifíricos hacia el centro) ¿no es precisamente contraria a la prevista?

HAY QUE DESAGREGAR EL GASO ARGENTINO

Pienso que el problema más grave que afecta a la teoría de la dependencia es el de su generalidad. Casi estaría de más recordar que no sólo hay cambiantes situaciones históricas, sino distintas magnitudes entre los Estados, y por ende diferentes márgenes de acción; y que tampoco son los mismos - según los países- los deseos políticos de sus gobernantes para mejorar las posiciones negociadoras. Sin embargo todo esto que de suyo es tan evidente, es necesario recordarlo visto el poco trabajo que se tomó la "teoría de la dependencia" en reconocer la existencia de situaciones diferentes dentro de América Latina.

¿Estará también de más recordar que constitutivamente -es decir, históricamente- el grado de vinculación para con los Estados Unidos ha estado en relación directamente proporcional a la pequeñez física del Estado latinoamericano, y a su proximidad geográfica con aquel "centro"? ¿Será inútil señalar que el grado de adscripción a la órbita europea ha estado también en relación directamente proporcional a la lejanía física y geográfica del país que dictó la Doctrina Monroe?

No compete a este trabajo analizar los casos de Brasil ni de Chile. Menos aún el de México, cuya sutil y aparentemente contradictoria trama de relaciones con los Estados Unidos lo excede. No voy a analizar el caso de aquellos países por no creerme capacitado, y por el temor de proyectar al conjunto del área -como ha ocurrido con muchos autores "dependentistas" - los casos particulares que mejor conocemos. Tengo que reconocer que en estas lí- 
neas me he planteado la relatividad teórica de esta temática porque estoy pensando "desde" la Argentina, y teniendo fundamentalmente en cuenta lo que ha ocurrido y está ocurriendo "en" la Argentina, un caso que bien podría ser atípico en América Latina, si bien lo suficientemente relevante para que esa atipicidad modifique la interpretación del todo.

La Argentina no es un país del Tercer Mundo (de los que ascienden colectivamente tras distintos procesos de liberación); por sus indicadores de desarrollo y modernización está ubicada en el rango $17^{\circ}$ entre los países independientes de más de 5 millones de habitantes. Antes -cuando tenía poca población e ilimitadas expectativas- lució los rangos que recordaremos. En esos estrictos términos analíticos sería un país que descendió de $1^{a}$ a $2^{\text {a }}$ división. Pero también esta media verdad es engañosa.

Hacia 1918 éramos segundos en el mundo, de acuerdo con el ingreso "per capita" (Clark, para años después nos ubica entre los 7 primeros; es lógico, 1918 fue un año anormal). Y éramos décimos por nuestras exportaciones, novenos por el monto total del comercio internacional, sextos (1930) por el parque automotor, y también sextos (1944) por la tenencia de oro. Buenos Aires ya era en 1914 una auténtica sociedad de consumo, y recibíamos anualmente contingentes de trabajadores centroeuropeos que venían a levantar la cosecha, porque el salario del peón agrícola que se pagaba en la pampa húmeda era -junto con la capacidad adquisitiva del pesosuperior a los de Italia, Austria y Ucrania.

Esto es un problema cuantitativo. La verdad es que al no controlar autónomamente sus resortes económicos la Argentina tenía por aquel entonces una relación neocolonial con Gran Bretaña. Y de tales cuantía y caljdad que en 1890 -al producirse una revolución y la consecuente crisis económica y monetaria- generó "corridas" en la Bolsa londinense (lo cito porque es un caso de reversión -aunque menor- de las relaciones centro/periferia, que también deben prever retornos).

Hay algo más que lo estrictamente económico: desde la primera Conferencia Panamericana (Washington, 1889) la Argentina devino -a juicio de los especialistas norteamericanos - implacable hostigadora de todo el sistema panamericano. Hasta el extremo de negarse en 1942 (conferencia de Río) a sumarse al esfuerzo colectivo del continente.

1) El "caso histórico" de la Argentina no es atípico en el esquema pero sí en la clirección. Porque el "centro" es otro.

a) la Argentina ha sido un país sin expoliación colonial. Aquí -en una tierra yerma- no hubo superposición, imposición ni sincretismo 
de culturas. No había nada. Lo que hubo fue continuidad hispánica en tierra americana (los dos hermanos varones de San Martín murieron como coroneles del Ejército Español, uno luchando por el rey en Filipinas). Desde el punto de vista económico, no hubo exacción (el actual territorio argentino no fue minero, como por ejemplo Bolivia, que se sitúa en sus antípodas). Hubo en cambio la multiplicación de los ganados que trajeron los españoles, y que abandonaron libremente en la pampa. Y el monopolio formal del comercio fue equilibrado por la magnitud del contrabando.

b) en la Argentina del siglo xix no se constituyeron enclaves. Aunque se podrían discutir detalles de las concesiones ferroviarias (menos dadivosas que las que por aquellos años se habían otorgado en Canadá y la India). Además los ferrocarriles no fueron privativos de los ingleses: después de 1880 hubo ferrocarriles franceses, y el Estado tomó a su cargo la realización de esas tareas para las áreas de explotación antieconómica. Contrariamente a la típica explotación colonial en la que los intereses imperialistas construyen primero una infraestructura para después controlar las exportaciones, en la Argentina la infraestructura se adaptó a la preexistente actividad productiva y exportadora pecuaria (del mismo modo que el tendido de rieles siguió los trazados que ya empleaban las mensajerías y carretas).

c) hasta 1914 el ingreso del capital externo fue inglés, y subsidiariamente alemán. El ingreso del capital norteamericano fue tardío en términos comparativos regionales. Hacia 1930 éramos cuartos en el mundo por el monto total de las inversiones directas británicas, y sextos igualmente por el de las norteamericanas.

d) hacia 1.918 éramos una auténtica colonia próspera (británica) dada la vulnerabilidad de nuestras exportaciones (la de carnes especialmente), la impenetrabilidad del mercado norteamericano, $y$ la cuantía y caliclad de las importaciones (hechas en Europa continental, subsidiariamente en Gran Bretaña, y por último en los Estados Unidos). En los años 30, ante el Tratado de Ottawa, con una industria frigorífica compartida por británicos y estadounidenses, ratificamos tratados (con cláusulas que nos acordaban un trato preferencial) que al garantizar nuestro acceso al mercado comprador inglés, convalidaban muestra situación neocolonial.

e) la sustitución de importaciones que realmente nos interesa comenzó en los años 20, y se acentuó en los 30. Fil proceso fue, pues, muy anterior al genérico de América Latina. En gran medida esa sustitución de importaciones se hizo a través del ingreso del capital norteamericano, que fue en la Argentina exclusivamente manufacturero (Pero atención, Ia sustitución de importaciones es un proceso permanente. Así, entre 1860 y 1880 se sustituyen alimentos, y 
cada período al poner el énfasis en diferentes artículos, resulta cualitativamente diferente).

f) el enfrentamiento de intereses (británico-norteamericano) dio siempre a la Argentina un "margen de maniobra", y le permitió discretamente sacar provecho de una relación triangular. El monto total de la inversión europea (británica más continental) fue muy superior al de la norteamericana. La nacionalización de los ferrocarriles británicos en 1947 modificó la relación pendular, al desaparecer la "tercera pata de la mesa".

2) Algunos datos constitutivos de la economía argentina tampoco se ajustan al esquema latinoamericano. Al contrario, una buena parte de sus estructuras productivas son diferentes. Supongamos que las pudiéramos definir con estas notas:

a) la de la Argentina es tan sólo una economía relativamente abierta. En el sentido de que la tendencia a cerrarse (al menos en su comercio exterior) ha sido una constante en el lapso 1938/1970 (Todavía no sabemos si lo registrado en 1973 implicará una modificación estructural.) Esta cerrazón se caracterizó por la invariable caída de la participación de sus exportaciones en el monto total del producto bruto nacional.

b) es vulnerable. En el sentido de que sus exportaciones básicas ("tradicionales") se centraron en algunos productos seleccionados; pero ahora en mucho menor medida que en períodos anteriores. $Y$ es vulnerable también porque debe importar insumos insustituibles para su desarrollo industrial, tanto como bienes de capital. ¿Pero qué economía no reconoce al menos un grado de vulnerabilidad? Ya citamos el caso de Japón. Pues bien, las autoridades gubernamentales norteamericanas anuncian que para 1955,9 de los 13 principales minerales indispensables a su desarrollo, tendrán que ser importados. Entre otros el cobre, el azufre y el petróleo.

c) está supeditada a los efectos de demostración (originados en las economías centrales). Pero este es un fenómeno universal del que ni la Unión Soviética se podrá escapar al corto plazo (y del que tal vez hoy sólo se libre Albania, que está rodeada de una auténtica "muralla china").

d) y cuya capacidad de decisión económica es relativamente independiente, porque quienes deben adoptar las decisiones políticas tienen ante sus ojos un "plafond" determinado por los montos del endeudamiento externo, sus problemas de financiación y los márgenes de disponibilidad de bienes. Ese "plafond" es debido -casi exclusivamente- a un deficiente manejo interno, y a la discontinuidad de las políticas económicas iniciadas en cada lapso.

Luego, el síndrome endeudamiento/pago de los servicios/endeu- 
damiento tal vez resulte un paliativo por no haberse querido enfrentar los problemas de fondo, o haber permitido los consumos suntuarios de una extendida clase media-alta acomodada. Pero este endeudamiento externo - a diferencia de lo que ocurre con otros de los "grandes relativos" del área- no ha establecido los parámetros para seleccionar las opciones que se presentaban al desarrollo. Porque en la Argentina, y desde hace entre 15 y 20 años, el ahorro interno ha financiado más del $90 \%$ de las inversiones totales. Más allá de los consabidos temas del área -expansión de las corporaciones multinacionales, problemas emergentes de la transferencia de tecnología, etc.- surgen algunos aspectos "diferenciales". Y el conjunto de estos diferenciales se podría sintetizar por la consabida proclividad de la Argentina hacia Europa.

a) en la Argentina el Estado controla todos los resortes básicos de la conducción económica del país: la explotación, producción y comercialización del petróleo (desde sus orígenes, pero con concesiones de explotación y comercialización según épocas), el gas, otros servicios públicos, el transporte (el ferroviario desde 1947), los sistemas de comunicación (teléfonos desde los años 40, comunicación por satélites, internacional, etc, desde 1970), de la electricidad en todas sus formas, de la extracción y explotación del carbón, del manejo de los sistemas bancarios y crediticio y del reaseguro.

(Entre 1966 y 1972 se vendieron paquetes de acciones de bancos privados originalmente argentinos -algunos fueron comprados por el Banco de Santander-y esos paquetes accionarios fueron readquiridos por el Estado en 1973).

b) el capital extranjero suele ser considerado como si constituyera grandes agregados, Io que es falso; corresponde formular su calificación por sectores. Ia siderurgia es en principio privativa del Estado, y sujeta a prioridades y controles de orden militar, que han Ilegado - por "razones de seguridad" inclusive- a vetar los acuerdos privados con las grandes corporaciones americanas. Pues bien, el complejo siderúrgico más importante de capital privado en el país es italiano.

c) de las 10 primeras empresas (1972, según monto de facturación), 6 son estatales (YPF, SEGBA, ENTEL, FERROCARRILES, SOMISA y CAP). Incluimos como estatal a la Corporación Argentina de Productores de Carnes, según el estatuto de 1973. La undécima era GAS DEL ESTADO ${ }^{8}$. Si lo que se analiza son las 50 primeras para ese mismo año, resulta: que 10 son estatales, 10 son privadas de capital argentino, 9 de capital norteamericano, 18 de capital europeo, y 3 mixtas. En esa lista de 1972 está incluida como

$8 \mathrm{El}$ listado de las 120 primeras empresas fue publicado por Mercado, del 13 de julio de 1972, Buenos Aires. 
estatal SIAM, que lo es a través del Banco Nacional de Desarrollo. $\mathrm{Si}$ en cambio las que se desagregan son las 100 primeras, de acuerdo con la composición de su capital (1970) resulta: que el $31 \%$ de este capital es estatal, el $27 \%$ de capital privado argentino (Corporación Argentina de productores de Carne, Celulosa, Sancor, Loma Negra, Sasetru, Gurmendi, Ledesma, etc., etc.), el $20 \%$ es de capital europeo, y el $19 \%$ de capital norteamericano. ${ }^{\theta}$

d) del conjunto de esas empresas, correspondería separar las dos del tope, tanto por razones cualitativas como cuantitativas; la primera es el complejo petrolífero estatal -YPF- y la segunda Fiat, fabricante en la Argentina no sólo de automotores y tractores, sino de material ferroviario. Pero esto es un problema de corte analítico, pues bajo el rubro Fiat se incluye a distintas sociedades. En cambio no ocurre lo mismo con el complejo nacional Bunge y Born que suele aparecer disociado en este tipo de listas. El complejo Bunge y Born sería así el segundo o tercero (tal como aparece año a año en las listas de "Fortune", tras YPF entre las 200 empresas más importantes del mundo, excluidas las de capital norteamericano).

e) dentro del sistema financiero, los bancos estatales (y alguno menor que es mixto) recogieron en 1972 el $55 \%$ de los depósitos, contra el $29,1 \%$ de los bancos de origen nacional y el $15,9 \%$ reservado a las filiales locales de otros extranjeros (el más importante de los cuales es el de Londres y América del Sud) ${ }^{10}$. Esto ocurrió en 1972, pero como antes recordamos, recientemente el Estado readquirió los paquetes accionarios de aquellos Bancos que originariamente argentinos, habían sido transferidos a otros adquirentes. Por lo cual en una futura evaluación, el porcentaje que corresponderá a los estatales (o mixtos) se acrecentará significativamente.

f) como es sabido, el primer producto de exportación de la Argentina es la carne industrializada. Cuando la Argentina era una "colonia próspera", es decir hasta 1938, exportaba el $81 \%$ de su producción industrializada al mercado británico (promedio 1934/38) que es más o menos el mismo porcentaje de las actuales exportaciones de Australia hacia los Estados Unidos. En cambio en 1969, diversificadas las ventas en un total de 75 países, el cupo hacia los Estados Unidos era del $34 \%$ del total, el de Gran Bretaña del $22,3 \%$ y el correspondiente al conjunto de Europa continental del $43,7 \%$. Cuando en 1971 la Argentina exportó todo tipo de productos - "tradicionales" y "no tradicionales"- a un espectro diferen-

9Roberto T. Alemann, "El capitalismo estatal argentino", en Politica y Economía, Buenos Aires, octubre de 1971 , No 7 .

10De acuerdo con el listado y discriminación hecha por Mercado sobre "Los 100 bancos más grandes (Argentina)", en su No 198, Buenos Aires, 26 de abril de 1973. 
ciado de 1.16 países, el flujo hacia Estados Unidos representó el $9,1 \%$ del total (porcentaje equivalente al de las ventas que se hicieron a Holanda), pero inferior al de Italia, que insumió el $15 \%$.

g) saliendo de este ámbito estrictamente económico, ¿será necesario recordar dónde y cómo se ha realizado el equipamiento militar? Desde 1.966 rige el "Plan Europa", en cuya virtud las adquisiciones se hicieron en países del Continente. La Fuerza Aérea se provee de "Mirages" y de los "Camberra" (este último es un avión inglés). Las adquisiciones de submarinos se hicieron en Alemania (por partes, y para el armado local, ya que teóricamente la República Federal no puede industrializar armamentos). Y las fragatas continuaron adquiriéndose en Gran Bretaña. ¿Será necesario recordar también que la misión militar extranjera más importante establecida en el país es la francesa (porque los tanques están montados sobre prototipos franceses), y que la doctrina de contrainsurgencia provino originariamente (en los años 60) del adoctrinamiento de los coroneles de ese país que vinieron invitados para transmitir sus experiencias de Argelia?

Es obvio que después hubo aspectos logísticos y de asignación de roles (policía interna) que provinieron de las fuentes doctrinarias de "desarrollo y seguridad" emanadas en los Estados Unidos. Pero esto es clemasiado conocido. Y aquí sólo hemos hecho el balance de los "diferenciales".

h) continuando con esta proclividad europea, dserá necesario indicar que según comprobaciones aquel continente sigue siendo el mayor centro de atracción para los cursos de post-grado y perfeccionamiento de los profesionales argentinos que van a estudiar al exterior? ( $\mathrm{El} \mathrm{49,3 \%}$ de los post-grados se han realizado en los países europeos, contra el $30 \%$ en los Estados Unidos, para la cohorte de becarios externos del lapso 1962/1969), dy que lo mismo ha vuelto a constatarse sobre los doctorados obtenidos en el exterior por los investigadores científicos de dedicación exclusiva?"1

i) por último, y sin necesidad alguna de realizar investigaciones específicas de socio-lingüística, ¿quién puede ignorar en América Latina que el "habla popular" de Buenos Aires está plagada de italianismos? (y del "xeneise", dialecto genovés). Pero ¿cuántos son los que saben que hasta el presunto genuino "che" identificatorio es valenciano?

11La investigación sobre la orientación de los post-grados externos fue realizada por la doctora Marta Mo, como estudio administrativo interno, e inédito, para el Consejo Nacional de Ciencia y Tecnología (SECONACYT), Buenos Aires, 1971. EI estudio sobre los investigadores científicos, corresponde a los de la planta permanente del Consejo Nacional de Investigaciones Científicas y Técnicas, fue realizada por José Luis de Imaz, a partir de una muestra representativa, en diciembre de I972. Igualmente inédito, y para uso administrativo. 
LA VENTA DE AUTOMJTORES A CUBA

Y LA INCORPORACIÓN DE TECNOLOGÍA SOVIÉTICA

Un conjunto de empresas internacionales -radicadas en la Argentina- mediante una acción concertada por el Gobierno, proyectaron la venta a Cuba de 42.000 unidades automotoras (camiones, tractores, autos, etc.), operación a 6 años de plazo, financiada con un crédito que es el más importante hasta la fecha abierto por país alguno del área a la Isla. Una de las empresas ofertantes, la Fiat, no tenía porque convalidar su operación. Las otras tres eran filiales locales de centrales americanas - Chrysler, Ford y General Motorssusceptibles de que se les aplicara la legislación estadounidense que sanciona a las empresas que no cumplan con los requisitos del bloqueo a Cuba (al menos eso era lo que hasta la fecha había impedido a Ford-Canadá realizar operaciones con Cuba).

El gobierno argentino sostuvo que el bloqueo a Cuba era ya anacrónico, y estaba modificado por los hechos. I que para la Argentina la carta-intención de venta era un acto de soberanía no sometido al contralor ni visto bueno de país alguno. Que las empresas, por más filiales que fueran, estaban constituidas en la Argentina, como sociedades anónimas nacionales, y sólo sometidas a sus leyes. Luego, no habiendo contradicción ni colisión de intereses, eran libres para estipular los convenios que quisieren. El laudo para el problema interno americano (es decir, la resolución del conflicto en ese país entre aplicar la ley federal o aceptar la extraterritorialidad de sus empresas) quedó en manos del presidente Nixon con el resultado por todos conocido. Al parecer, en el laudo hubo que sopesar muchos elementos contradictorios; no sólo en enfrentamiento entre los intereses políticos del Estado y los económicos de las empresas, sino hasta la presión de las compañías competitivas que habían adherido al principio del bloqueo. Innecesario pareciera destacar que, para el caso, no nos interesa tanto la relación económica de la Argentina con Cuba, como la aceptación de la plena vigencia de la soberanía local, es decir la prevalencia del hecho político que enmarca un "estatuto nacional" para las empresas multinacionales. Y además está, por supuesto - pero en segundo término- la brecha abierta, la ruptura del bloqueo, acto unilateral realizado por un país. Y todo lo emergente: es decir, que frente al hecho cumplido se produjo una fisura en el sistema de las relaciones políticas interamericanas. 
De ahí que no nos resulte tan importante lo que pueda ocurrir tras la reunión de cancilleres, convocada para fines de 1974, ni que, como consecuencia, Cuba ingrese o no a la Organización de los Estados Americanos. Incluso es muy posible que no quiera hacerlo; tal vez para reservarse su propio juego político, y quedar liberada de las reglas del institucionalizado.

Hay dos aspectos que me importa señalar: primero la expectativa de una reforma a la Carta de la Organización de los Estados Americanos (ya iniciada en la Conferencia de Lima, 1973), y después que la primera potencia del mundo perdió en este caso la capacidad de iniciativa, teniendo que adecuar sus comportamiento y estrategia a lo realizado por otros (esquema que resultaría impensable en una interpretación sólo verticalista de las relaciones).

Creo además que es en este mismo contexto de apertura que deben considerarse los otros "hechos nuevos" modificatorios de las reglas del comercio internacional. Así por ej. la decisión adoptada por la Comisión Mixta argentino-uruguaya de adjudicar a la Unión Soviética los contratos para la producción de generadores de turbinas en la presa de Salto Grande. E igualmente -al momento de escribir estas líneas- los primeros resultados de la misión económica argentina que en Rusia, Checoslovaquia, Polonia y Hungría busca el intercambio de productos manufacturados por la absorción de tecnología de los países socialistas, en la explotación carbonífera, equipos petroleros de perforación, turbinas hidroeléctricas y equipamiento de pesas. Gestiones todas éstas que más allá de la firma de algunas cartas de intención, se han concretado ya en el mayor crédito de desarrollo abierto hasta la fecha por la Unión Soviética a país alguno de América Latina (salvo Cuba por supuesto), y en la posibilidad de la concreción de sociedades mixtas para las ramas de la economía antedichas.

\section{ALGUNAS CONCLUSIONES PARA ESTE "COLlAGE" ANAIÍ́TICO}

Lo que antecede es un "collage" analítico en el que se han incluido algunos temas y excluido otros. Ejemplo acabado, me parece, de lo inasible que resulta esta problemática. Demostración palmaria -por último- de los peligros corridos por una teoría que ha hecho un tremendo esfuerzo inclusivo, es decir que ha estirado datos de la realidad hasta ubicarlos en el mismo paréntesis explicativo.

Pero a mi ver, y sin perjuicio de lo dicho en otras páginas, creo que al término del "collage" se podrían señalar algunas conclusiones que corresponden a planos diferentes. 
19) La calificación de las inevitables situaciones de subordinación es un problema de grados y de magnitudes.

De grados, porque las relaciones de dependencia podrían arbitrariamente desplegarse como si fueran una escala sismográfica.

En otras palabras: así como la escala sismográfica se extiende del 1 al 12, así también las relaciones verticales y asimétricas entre dos pueblos podrían medirse en forma parecida. Donde habría que tener en cuenta que el poder de una superpotencia no siempre es potencial ni realmente empleable. Y que las arenas, métodos y formas del enfrentamiento están dadas por los estrechos márgenes en que se mueve el contendiente más débil.

Además habría que prever que si 12 fuera el puntaje para el país integralmente sometido, no sería 1 el de las superpotencias. Sino 3, - a lo mejor 4. Pues tal es la carga de sus respectivos liderazgos mundiales, que éstas devienen, en menor medida, reversibles y condicionantes.

En efecto, ¿qué país del mundo no es en alguna medida, “dependiente"? Tomemos el caso del comercio internacional: los Estados Unidos retenían en 1970 el $15 \%$ de las importaciones mundiales, Rusia el $4 \%$, Japón el $6 \%$, Gran Bretaña el $7 \%$ y Alemania Federal el $10 \%$. Porque Estados Unidos, no sólo por la necesaria futura importación de materiales críticos, sino hasta por los "datos" del presente, no podría abstenerse de estas importaciones. Porque el levantamiento aun parcial de ciertas reglas del comercio internacional le generaría tales costos políticos que complicarían sobremanera sus objetivos de país-líder.

Todo esto de la dependencia -aunque parezca una verdad de perogrullo- es un problema de magnitudes, es decir de posibilidades. Es sabido que el desarrollo integral de un pueblo está determinado entre otras cosas por la combinación favorable de una serie de factores: recursos naturales, existencia de centros urbanos generadores, y la capacidad creativa de sus hijos (es decir que lleguen a combinar felizmente las eficiencias económica, administrativa y tecnológica).

Pues bien, la segunda verdad de perogrullo - pero que por cortesía se suele ocultar - es que hay naciones nominalmente independientes que no podrán ser otra cosa que dependientes (al menos mientras quieran preservar su nominal soberanía jurídica). Es un problema de escala, es un problema de tamaño. Porque el proyecto de autonomía de muchos países - a esta altura del mundo- sólo puede pertenecer al dominio de la utopía.

29) Hay que cuestionar la validez explicatoria de una teoría tan omnicomprensiva.

Es decir, no creo en la validez ni en la perdurabilidad del parén- 
tesis teórico elaborado, sobre todo en un mundo tan aceleradamente cambiante. Creo en cambio en la existencia de "relaciones de dependencia específica". Por ej. en las tácticas económicas originadas por el gigantismo futuro de las empresas transideológicas, las dificultades de todo orden en la problemática de la transferencia de tecnología, en los "costos" de no recibirla por empecinamiento, y en los "costos" de no haberla generado por pereza imaginativa, etc., etc.

El paréntesis analítico "dependencia" es un odre relativamente nuevo, para viejos vinos. Muchos de los cuales son valederos, caso por caso. Pero mi temor - tal lo anticipado- es que el odre se convierta en un absoluto explicatorio, y en un auto-justificativo de nuestra inercia y falta de responsabilidad. $Y$ por ende en un escamoteo de intransferibles problemas.

Seamos teóricamente más humilde. Porque me parece que con esto de la "dependencia" ocurrirá a la postre lo mismo que con el "desarrollo". Ambas dos, en su momento, preocupaciones casi exclusivas, verdades parciales que convertidas en "ismos" absorbieron todas nuestras energías. Volvamos a la reciente convocatoria a una mayor humildad explicativa. Supongamos que para el análisis sociológico de un país concreto, correspondiera detectar un grupo de problemas relevantes y constitutivos. Y que esos intransferibles problemas debieran ser analizados al través de algunas de las teorías en boga. Pues bien, si en mis manos estuviera, me atrevería a señalar 5 prioridades como otros tantos problemas sociales en la Argentina:

1) la magnitud de las diferencias regionales (inferiores a las del Brasil, pero superiores a las de Australia y Canadá),

2) un sistema educacional contradictorio: con una baja tasa de analfabetismo, alta deserción primaria, mínima especificidad secundaria, superpoblación miversitaria, y una inevitable proyección hacia un "proletariado" profesional,

3) un sistema de ingresos económicos de alta concentración en la cúspide, un décimo de su población marginada de los bienes sociales potencialmente apetecibles, y una distancia salarial de 40 a 1 , en los extremos de la escala perceptiva,

4) una población urbana (Buenos Aires) que exhibe tasas muy elevadas de movilidad social ascendente, y que genera un proletariado (y una clase media y alta) de exacerbado individualismo,

5) un sistema político signado por la discontinuidad.

Si esto es así, si estos fueran los "irrenunciables" problemas ¿qué grado explicatorio les habría de deparar la teoría de la dependencia? Es decir ¿qué relación de causa a efecto -inmediata, directa, y no remota o secundaria- es la que nos podría facilitar?

Entonces, si no es así, si no es capaz de explicarnos los "intrans- 
feribles", ¿por qué le asignamos un rol tan relevante? ¿Por qué la convertimos en central si no nos puede interpretar lo central?

$\left.3^{\circ}\right)$ La apertura de la temática ha sido funcionar y su implementación depende de una voluntad política.

Pero aquí ya entramos a hablar de otra cosa, como por ej. del carácter de servicio público que debe tener la ciencia social. Y donde la problemática vuelve a enraizarse con un voluntarismo que no me asusta, y en la que convergen nuestras preocupaciones por la posible maximización de la autonomía.

¿La autonomía se identifica en todos los casos con lo bueno? ¿to instrumental con los fines últimos? ¿La mítica liberación con la plenitud de nuestras posibilidades colectivas? ¿El nacionalismo de medios no resultará a la postre disfuncional al nacionalismo de fines?

Sería infantil responder a todo que sí. No hay cambio que no se haga dolor. No hay cambio -aun en el caso hipotético de que hubiere sido minuciosamente pensado- que no genere efectos secundarios y hasta no queridos. Además es un problema de magnitudes, de sagacidad en la conducción y hasta de estrategias empleadas. Y de saber estirar las posibilidades hasta el punto de no ruptura.

La implementación aneja a la problemática de la dependencia es un problema de hombres (hombres corruptibles, y predispuestos a ser "comprados" por unos u otros fondos, siempre los ha habido en América Latina, y los habrá), pero es además un problema de decisiones políticas, y de continuidad en esas decisiones. No ha habido país con mayores inversiones extranjeras en su territorio a lo largo del siglo XIX, y hasta 1914, que los Estados Unidos. La Unión Soviética dio un paso atrás para recibir y capacitarse en la tecnología que no tenía. Y es indudable que Europa en los años que siguieron a la $2^{\text {a }}$ Guerra Mundial fue dependiente de los Estados Unidos en términos de ayuda para la reconstrucción económica, de protección militar, y hasta de salvaguardia de su estabilidad política.

1Todo es tan entremezclado, tan cambiante, tan móvil en este tema! [Todo es tan inasible cuando se lo trata de estudiar empíricamente! Todo hasta tal punto nos evidencia la vanalidad teórica de los terribles simplificadores... 